\title{
Analysis on Brand Value Evaluation and Management
}

\author{
Jicheng $\mathrm{Li}$ \\ School of Management, Harbin University of \\ Science and Technology, \\ Harbin 150080, Heilongjiang
}

\author{
Fangfang Wang \\ School of Management, Harbin University of \\ Science and Technology, \\ Harbin 150080, Heilongjiang
}

\begin{abstract}
Brand is an important intangible asset of enterprises and plays a vital function in building up a good external image of enterprises. Enterprise brand plays a positive role in relieving the contradictions of product supplies to some extent and then brings about excess profits and value for the healthy development of enterprises. With the continuous development of the market economy, brand value evaluation and effective management in enterprises become important ways to comprehensively improve the overall business image. In this paper, the effective brand value evaluation and management measures are mainly analyzed, aiming to provide a reference for effectively playing the important role of brand in the long-term development of enterprises.
\end{abstract}

Keywords- Brand Value; Brand Management; Evaluation; Economic Construction

\section{Introduction}

With the constant development of the world economy, the domestic and international market competition pressure is getting increasingly great; China's original seller market gradually changes to the current buyer market, and consumers have more autonomy to make a choice in market transactions. In such a development situation, how to make use of the self-brand advantage and create more favorable overall image of enterprise has been an important problem of realizing economic sustainable development. Therefore, effective enterprise brand value evaluation and management have been the main measures to improve an enterprise's comprehensive competitiveness.

\section{An overview of brand and brand value}

\subsection{Brand}

Enterprise brand represents an enterprise's external image, business management, and cultural construction, and features exclusiveness, risk and extensibility. First, enterprise brand owns the sole power to a certain extent, so an enterprise has the right to ask other enterprises or individuals not to forge. Second, enterprise brand has risk characteristics. Enterprise brand needs to undergo for a long time from its construction to application, so it is with great risk. Finally, enterprise brand is extensible. Enterprise brand belongs to a kind of intangible resources, and an enterprise can use its popularity to continuously expand the market and develop more new customers. In addition, enterprise brand has a function of recognition to some extent; the effective advantages of a brand can be used for guiding enterprises to constantly achieve market expansion.

\subsection{Brand value}

Brand value is a form of value that is commonly recognized by consumers in an essential sense. If an enterprise's brand is not widely accepted by the consumers, the essential purpose is hard to achieve even if more time is costed. Although brand value is fundamentally attributed to enterprises, the subjects able to create business brand value are not only enterprises, but directly, closely related to consumers. When an enterprise is creating a brand and playing its value, consumers as an important part play their own 
independent right to make a choice and ultimately achieve the brand value.

\section{Brand value evaluation method}

\subsection{Cost}

In brand value evaluation ways, there are two different ways of calculation in the cost method. One way refers to implementing an effective evaluation on the original value in the development and purchase of enterprise brand asset, which is also known as historical cost calculation method. The other refers to multiplying brand replacement cost and newness rate and using the product as the representative of the enterprise brand value evaluation, which is also known as the replacement cost calculation method. But most enterprise brands are divided into two types: self-brand and purchased brand. First, the self-brand replacement cost does not possess the book value; brand cost is evaluated only according to the existing relevant expenses standards. Second, for purchased brand, enterprise mainly uses the book value as the main basis for its evaluation and also implements an effective adjustment to price index.

\subsection{Market}

Market evaluation method is mainly based on the principle of substitution: the recent trading value of similar or identical assets in the market environment is used as the foundation, and the value of asset is estimated using direct or analogical method. There are two market evaluation methods: direct and similar comparison calculation methods. The direct comparison method refers to choosing the similar enterprise brands as the main objects of reference and using the current market value to reduce the price of the total depreciation amount in the service life for carrying out the brand value evaluation. The similar calculation method means that the relevant personnel seek and evaluate the project similar brand types in the market and establish different comparable items to carry out target comparison and obtain the relevant results.

\subsection{Income}

Income method refers to the sum of different evaluation methods for estimating and predicting the present value of the assets according to the future income and effectively judging the related assets. This method mainly involves three aspects: (1) the expected income of the evaluated asset object, which mainly features future and objective earnings; (2) the capitalization rate value; (3) the length of time maintained by the expected benefits of the evaluated objects, which is called as the period of income.

\subsection{MSD}

MSD, as an evaluation method, gives a full consideration to the domestic economic development characteristics, but also provides compromising process. In this paper, the evaluation method is improved, aiming to add consumers' awareness, loyalty, and connection degree, and purchasing power into the future development potential of brand.

\section{The practical significance of the brand value management}

\subsection{The key of enterprise development}

In enterprise brand management, all internal resources are effectively integrated and optimally set up; the maximization of the interests of enterprise is regarded as the main development goal. The current market economy environment is changeable, and therefore, enterprises need to constantly improve the self-brand value and the value management under the fierce market competition situation, so as to provide helps for enterprises to obtain a sustainable development motivation. In addition, brand, as a guide for the overall direction of the development of enterprise, can help related decision-making and management personnel to raise accurate strategies and improve innovative management 
in the value management process; an internal improvement management system is internally established to promote the enterprises to achieve a long-term development.

\subsection{Realizing the benefit maximization}

The maximization of enterprise value requires the values of different aspects in an enterprise to achieve synchronous development and promotion and is not only limited to shareholder value. To some extent, enterprise is a social organization and needs to generate a wide economic connection with other organizations and bear important social responsibilities in the normal course of business. Therefore, enterprise brand value management is an actual need of enterprises to achieve maximum benefit.

\subsection{Improving business operating efficiency}

In the process of enterprise economic operation, brand value is the most effective standard for evaluating the development efficiency. In band value management, the daily enterprise management behaviors and strategy implementation are efficiently combined and then regarded as important driving elements for an enterprise to analyze the key value, determine the financial performance indicators of every department and finally assign them to each department, and use them as the main factors of the performance evaluation.

In addition, the evaluation indexes are used to the value creation and addition of enterprise as well as different departments, and this is helpful for each department to know well the actual operating efficiency.

\section{The application of MRG to enterprise brand value evaluation and management}

In this paper, MRG value evaluation method is improved, and a domestic brand is taken for example to discuss the effective use of the brand value evaluation and management.

\subsection{MRG evaluation method}

The original of MRG evaluation method was MSD evaluation. MRG evaluation model includes three parts: comprehensive multiplier, the brand's market share, and the brand value' excess capacity. The main difference is concentrated on the synthesis multiplier and mainly refers to considering enterprise brand's comprehensive development potential and the competitiveness of the brand created by consumers. In the model, consumers are fully taken into consideration; consumers' cognition, connection degree, and loyalty are added, aiming to carry out weight analysis and promote the enterprise brand value evaluation process to be integral.

\subsection{The application of MRG to enterprise brand value evaluation and management}

Wong Lo Kat in 2012 is taken for example to expound MRG evaluation method. The brand is a product of Guangzhou Pharmaceutical Holdings Limited and has developed for more than two hundred years, so it has occupied a larger share in the market and grown into a well-known herbal tea brand at home and abroad in the constant innovation and efforts. In 2010, Guangzhou Pharmaceutical Holdings Limited announced its value exceeded 100 billion RMB and gradually made its contradiction with JDB to the public, and created a larger range of brand competition.

The improved brand value evaluation method was applied to calculate the brand's market share, overbalance creation value and comprehensive development potential. In the process of calculation, the brand's annual financial statement was necessarily queried for determining its annual sales income. In addition, the asset appraisal results made by the asset appraisal company were analyzed and queried for determining the brand's overall evaluation value. Meanwhile, the strength of the brand was determined, mainly involving market, stability, leadership and so on. The market refers to the target market playing an effect. Stability refers to 
the related fixed number of years for a brand to actually survive. Leadership refers to the brand's pricing and its effective capability to lead the industry standards. Internationalization refers to the actual acceptance of this brand within the scope of the international market. Support refers to the sustainable investment and the effective degree of supports for the brand. Protection refers to the degree of the protection for this brand.

Brand value evaluation professionals gave scores to the related data of the brand, determined the weight of each factor and the consumers' cognition degree, loyalty, connection degree, and purchasing power, and solved the consumers intensity values in combination with the fuzzy hierarchy analysis way.

Contrast and survey found that the value of the brand declined by 28.5333 billion $\mathrm{RMB}$ in 2010-2012. Seen from the statistics, the brand value showed a decline trend, mainly because of the fierce market trend competition and inappropriate marketing methods. However, the data also needed further investigation, and its representativeness needed further analysis and confirmation. The results obtained by different brand evaluation ways were different to some extent. Therefore, the author thinks that enterprise brand value evaluation should not be confined to the numerical value level and the expressive value of brand value in currency is necessarily analyzed from a rational angel so as to provide a reference for enterprises to achieve a long-term development.

\section{Conclusion}

Ways of evaluating enterprises brand value are diversified. Brand value occupies an important part in the overall economic benefit development of an enterprise. But in the quantitative analysis process, how to effectively control the degree is one of problems difficult to solve, but also an important reason why different evaluation results are produced with different evaluation methods. In this paper, the related definitions and characteristics of brand and brand value are analyzed, and then brand value evaluation methods and the practical significance of brand value management are introduced, and finally the effective application of MRG to brand value evaluation and management is analyzed with real case, so as to help enterprises to achieve a long-term development.

\section{References}

[1] Lei Zhang. Master Kong Brand Evaluation and Analysis [D]. Southwest University of Finance and Economics, 2014.

[2] Mengyi Ju. High and New Technology Enterprise Brand Evaluation based on the Real Option Law [D]. Yunnan University, 2015.

[3] Jiarui Yang. Real Estate Brand Value Evaluation Method and Its Application Research [D]. Beijing Jiaotong University, 2015.

[4] Shaolan Tan. Enterprise Brand Value Evaluation Research [D]. Hebei Economic and Trade University, 2014.

[5] Xu Han. Brand Value Evaluation Method Improvement and Case Study [D]. Southwest Jiaotong University, 2014. 